OPER UND WERKTREUE 


\section{OPER \\ UND WERKTREUE}

Fünf Vorträge

Herausgegeben von Horst Weber

Verlag J. B. Metzler

Stuttgart - Weimar 
Die Deutsche Bibliothek - CIP-Einheitsaufnahme

Oper und Werktreue ; Fünf Vorträge / hrsg. von Horst Weber.- Stuttgart ; Weimar : Metzler, 1994

ISBN 978-3-476-01267-8

NE: Weber, Horst [Hrsg.]

ISBN 978-3-476-01267-8

ISBN 978-3-476-03569-1 (eBook)

DOI 10.1007/978-3-476-03569-1

Dieses Werk einschließlich aller seiner Teile ist urheberrechtlich geschützt. Jede Verwertung außerhalb der engen Grenzen des Urheberrechtsgesetzes ist ohne Zustimmung des Verlages unzulässig und strafbar. Das gilt insbesondere für Vervielfältigungen, Übersetzungen,

Mikroverfilmungen und die Einspeicherung und Verarbeitung in elektronischen Systemen.

(C) 1994 Springer-Verlag GmbH Deutschland

Ursprünglich erschienen bei J. B. Metzlersche Verlagsbuchhaltung und Carl Ernst

Poeschel Verlag GmbH in Stuttgart 1994 


\section{Inhaltsverzeichnis}

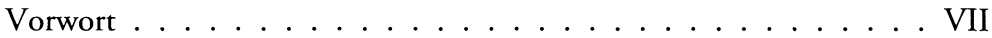

Zum Geleit $\ldots \ldots \ldots \ldots \ldots \ldots$. . . . . . . . . . . .

Horst Weber

Vom "treulos treuesten Freund"

Eine Einführung in das produktive Dilemma des Regietheaters . . . . 1

Sabine Henze-Döhring

Partitur und Aufführung

Exempel: Johann Christian Bachs Catone in Utica . . . . . . . . . 17

Jürgen Schläder

Mann oder Frau - stimmliche Charakteristika der Orpheus-Rolle

in Chr. W. Glucks Orpheus und Eurydike . . . . . . . . . . . . . . . 31

Jürgen Schläder

Wovon erzählen Hoffmanns Erzählungen? -

Operninszenierungen als Quellen-Manipulation ....... 51

\section{Dietmar Holland}

Lulu zwischen "Vollendung und Verwässerung «?

Zur Frage der "Vollendbarkeit" des dritten Aktes . . . . . . . . . . 67 


\section{Vorwort}

Vom 9. bis 12. Mai 1991 fand im Rahmen der Karlsruher Theatergespräche'91, die unter dem Motto "Opernbearbeitung oder Die Chimäre der Werktreue" standen, ein Symposium statt, das vom Bund der Theatergemeinden e. V. veranstaltet wurde und dessen Beiträge in diesem Band veröffentlicht werden.

Nach dem einleitenden Essay, der in die historischen Voraussetzungen und aktuellen Bedingungen des sogenannten Regietheaters einführt, entfalten die folgenden vier Vorträge einen historischen und systematischen Überblick über die Probleme, die sich bei der Inszenierung von Opern stellen. Aus dem 18. Jahrhundert wird mit Johann Christian Bachs Catone in Utica - einer "Opera seria", die wie die meisten Werke dieser Gattung nicht zum Repertoire des Musiktheaters gehört - eine Oper vorgestellt, deren Partitur nicht die Verbindlichkeit eines Werks beansprucht, mit Glucks Orpheus und Eurydike eine 'Reformoper', die aufgrund ihrer ästhetischen Funktion zwar den Anspruch auf die Verbindlichkeit eines Werks stellt, seiner Einlösung aber durch die Besetzung der männlichen Titelrolle erhebliche Schwierigkeiten bereitet. Hoffmanns Erzählungen von Offenbach steht, als Beispiel aus dem 19. Jahrhundert, für die Aufgabe, den fehlenden Schluß aufgrund dramaturgischer Überlegungen sinnvoll zu ergänzen, und das 20. Jahrhundert ist mit Bergs Lulu präsent, an der die Problematik erörtert wird, einen Teil des musikalischen Textes, nämlich die Instrumentation, zu vollenden. Alle diese Werke sind in jeweils besonderer Weise auf Bearbeitung angewiesen, sollen sie auf der Bühne realisiert werden, und die Weise ihrer Bearbeitung hat den unterschiedlichen Werkcharakter zu berücksichtigen, der je nach historischem Kontext in ihnen unterschiedlich ausgeprägt ist.

Herausgeber und Vortragende danken dem Bund der Theatergemeinden als Veranstalter, der die Drucklegung des Berichts finanziell gefördert hat.

Essen, im Mai 1994

Horst Weber 


\section{Zum Geleit}

Bei Diskussionen unter Opernfreunden über ungewöhnliche Produktionen bekannter Stücke kommt meist der Begriff der Werktreue ins Gespräch. Sie wird als Postulat und als Bewertungsmaßstab verstanden, vor allem von denjenigen, die beim Opernbesuch nur Vertrautes wiederfinden möchten. Sie verstehen sich als Anwalt des Komponisten, dessen Intention nicht verfälscht werden dürfe. Mit diesem Argument sieht sich jeder konfrontiert, der Bearbeitungen nicht grundsätzlich ablehnt. Solche Diskussionsmuster gibt es auch in den Theatergemeinden.

Bei der Vorbereitung der Karlsruher Theatergespräche 1991 bot Generalintendant Könemann an, innerhalb der Tagung eine Neufassung von Tschaikowskys Pique-Dame aufzuführen. Auch hier kam wieder die Werktreue ins Gespräch. Bei der gründlicheren Beschäftigung mit diesem Problem festigte sich die Einsicht, daß man sicher viele Opernbearbeitungen infrage stellen kann, daß aber die Forderung nach Werktreue als Begründung für eine Ablehnung meist zu wenig substantiell, oft geradezu falsch ist. Werktreue also eine Chimäre? - So etwas wollte mancheiner selbst als Frage nicht gern hören. Als sich aber in den Fachgesprächen zeigte, wie spannend und vielseitig dieses Thema war, wurde es schließlich akzeptiert, zumal offensichtlich manchem Opernfreund ganz neue Einsichten zu vermitteln waren.

Die Tagung selbst erwies sich als äußerst ergiebig, dank dem Engagement der Referenten. Wir freuen uns sehr, daß sie ihre Vorträge zum Druck bearbeitet haben, so daß die hier vorliegende Publikation erscheinen kann, als Anregung für weitere Erörterungen.

Prof. Dr. Walter Scheele

Vorsitzender des Arbeitskreises Musiktheater im Bund der Theatergemeinden.

Friedrich v. Kekulé

Präsident des Bundes der Theatergemeinden e.V. 